\title{
Excess of miRNA-378a-5p perturbs mitotic fidelity and correlates with breast cancer tumourigenesis in vivo
}

\author{
S Winsel 1,2,8,J Mäki-Jouppila1,2,3,8, M Tambe ${ }^{1,2,3,8}$, MR Aure ${ }^{4}$, S Pruikkonen ${ }^{1,5}$, A-L Salmela ${ }^{1,6}$, \\ T Halonen $^{2}$, S-K Leivonen ${ }^{4,7}$, L Kallio ${ }^{1}$, A-L Børresen-Dale ${ }^{4,7}$ and M J Kallio*,1,2 \\ ${ }^{1}$ VTT Health, VTT Technical Research Centre of Finland, 20520 Turku, Finland; ${ }^{2}$ Centre for Biotechnology, University of Turku, \\ 20520 Turku, Finland; ${ }^{3}$ Drug Research Doctoral Programme and FinPharma Doctoral Program Drug Discovery, University of Turku, \\ 20520 Turku, Finland; ${ }^{4}$ Department of Genetics, Institute for Cancer Research, Oslo University Hospital, 0310 Oslo, Norway; ${ }^{5}$ Turku \\ Doctoral Programme of Molecular Medicine, University of Turku, 20520 Turku, Finland; ${ }^{6}$ Turku Graduate School of Biomedical \\ Sciences, University of Turku, 20520 Turku, Finland and ${ }^{7}$ The K.G. Jebsen Center for Breast Cancer Research, Institute for Clinical \\ Medicine, Faculty of Medicine, University of Oslo, 0424 Oslo, Norway
}

Background: Optimal expression and proper function of key mitotic proteins facilitate control and repair processes that aim to prevent loss or gain of chromosomes, a hallmark of cancer. Altered expression of small regulatory microRNAs is associated with tumourigenesis and metastasis but the impact on mitotic signalling has remained unclear.

Methods: Cell-based high-throughput screen identified miR-378a-5p as a mitosis perturbing microRNA. Transient transfections, immunofluorescence, western blotting, time-lapse microscopy, FISH and reporter assays were used to characterise the mitotic anomalies by excess miR-378a-5p. Analysis of microRNA profiles in breast tumours was performed.

Results: Overexpression of miR-378a-5p induced numerical chromosome changes in cells and abrogated taxol-induced mitotic block via premature inactivation of the spindle assembly checkpoint. Moreover, excess miR-378a-5p triggered receptor tyrosine kinase-MAP kinase pathway signalling, and was associated with suppression of Aurora B kinase. In breast cancer in vivo, we found that high miR-378a-5p levels correlate with the most aggressive, poorly differentiated forms of cancer.

Interpretation: Downregulation of Aurora B by excess miR-378a-5p can explain the observed microtubule drug resistance and increased chromosomal imbalance in the microRNA-overexpressing cells. The results suggest that breast tumours may deploy high miR-378a-5p levels to gain growth advantage and antagonise taxane therapy.

MicroRNAs (miRNAs) are small non-coding RNAs that posttranscriptionally regulate gene expression via imperfect base pair binding primarily to the $3^{\prime}$ untranslated region ( $3^{\prime} \mathrm{UTR}$ ) of the target mRNAs (Pillai et al, 2007). Typically, miRNA binding results in target mRNA degradation or translational repression, thereby causing loss of function at the protein level. To date, more than 1500 human miRNAs are known to exist and over half of all human genes are predicted to be repressed by miRNAs (miRBase; http://www.mirbase.org/). Interestingly, $\sim 70 \%$ of miRNAs are intragenic and have the same orientation as the host gene, leading to their co-expression and possibly even to co-regulation of a particular cellular event (Rodriguez et al, 2004; Baskerville and Bartel, 2005). One miRNA can bind to mRNA of dozens of genes and one gene can be targeted by several miRNAs. In this way, miRNAs compose a vast signalling circuitry that a substantial amount of literature has linked with the control of diverse

*Correspondence: Dr MJ Kallio; E-mail: marko.kallio@vtt.fi

Received 8 May 2014; revised 25 August 2014; accepted 8 September 2014; published online 30 September 2014 
physiological and developmental processes including cell proliferation, differentiation and apoptosis (He and Hannon, 2004). MiRNAs are also deregulated in human pathological conditions such as cancer that can promote aggressive cell proliferation and invasive behaviour of cancer cells (Lovat et al, 2011) and cause resistance to anticancer therapies (Blower et al, 2008).

Mistakes in cell division are a potential source of numerical chromosome instability (CIN) and aneuploidy (Li et al, 2009; Musacchio, 2011). The spindle assembly checkpoint (SAC) is an evolutionarily conserved safeguard mechanism that controls fidelity of mitosis (Musacchio, 2011). The SAC delays chromosome segregation in the presence of defective microtubule-kinetochore interactions and spindle damage that allows time for error correction, thereby limiting production of daughter cells with genomic imbalances. Strong evidence from mouse models proposes that altered expression of SAC proteins leads to aneuploidy that can initiate and promote tumourigenesis, and cause tumour relapse after chemotherapy (Dobles et al, 2000; Sotillo et al, 2007; Weaver et al, 2007; Sotillo et al, 2010). One critical regulator of SAC is Aurora B kinase that works in concert with the other subunits of the chromosomal passenger complex (CPC) to control many mitotic processes (van der Waal et al, 2012). Loss of Aurora B function perturbs SAC signalling in cells resulting in polyploidisation (Kallio et al, 2002; Honda et al, 2003), whereas overexpression of Aurora B has been observed in several tumour types and is linked with a poor prognosis of cancer patients (Carter et al, 2006).

Whether and how miRNAs contribute to mitotic signalling is poorly understood. To identify miRNAs that possess anti-mitotic potency, we performed a cell-based high-throughput screen (HTS) and here report miR-378a-5p as a regulator of mitotic fidelity and provide evidence linking its overexpression to breast cancer tumourigenesis in vivo. The miR-378a-5p is located at chromosome $5(5 \mathrm{q} 32)$ where it resides in the first intron of PPARGC1B (PGC-1 $\beta, P E R C)$ and is coexpressed with this host gene that works as a co-activator of transcription factors such as the oestrogen receptor- $\alpha$ (ER; Kressler et al, 2002) and oestrogen receptor-related receptors (ERRs; Kamei et al, 2003). Earlier work has demonstrated roles for miR-378a-5p in the promotion of cell survival, tumour growth and angiogenesis through stimulation of Gli-1-mediated transcription; miR-378a-5p directly represses SuFu and Fus-1 that normally keep Gli-1 in check (Lee et al, 2007). Moreover, excess miR-378a-5p is implicated in the upregulation of angiogenic growth factor VEGF-A (Hua et al, 2006). Finally, miR-378a-5p participates in the regulation of energy metabolism via targeting $\mathrm{ERR} 3 / \gamma$ and $\alpha$-subunit GA binding protein transcription factor (GABPA) that are connected to the Warburg effect in breast cancer cells (Eichner et al, 2010). Here we show that excess miR-378a-5p impairs genomic balance and associates with suppression of Aurora B kinase. Moreover, we provide evidence linking miR$378 \mathrm{a}-5 \mathrm{p}$ overexpression to breast cancer tumourigenesis in vivo.

\section{MATERIALS AND METHODS}

Cell culture. HeLa cells were cultured in DMEM supplemented with penicillin/streptomycin $\left(0.1 \mathrm{mg} \mathrm{ml}^{-1}\right)$, glutamine $(2 \mathrm{mM})$, non-essential amino acids (0.1 mM), HEPES (20 mM), sodium pyruvate $(1 \mathrm{~mm})$ and $10 \%$ fetal bovine serum. For HeLa H2B-GFP cells, blasticidin was added to the culture medium $\left(2 \mu \mathrm{g} \mathrm{ml}^{-1}\right)$. The HCT-116 cells were cultured in McCoy's 5A medium supplemented with penicillin/streptomycin $\left(0.1 \mathrm{mg} \mathrm{ml}^{-1}\right)$, glutamine $(2 \mathrm{~mm})$ and $10 \%$ fetal bovine serum. The cells were cultured at $37^{\circ} \mathrm{C}$ supplied with $5 \% \mathrm{CO}_{2}$.

High-throughput screen. To screen for anti-mitotic miRNAs, 20 nм Human Pre-miR miRNA Precursor library v2 (319 molecules;
Ambion, Austin, TX, USA) or $20 \mathrm{~nm}$ miRIDIAN microRNA mimic library v10.1 (810 miRNAs; Dharmacon, Lafayette, CO, USA) was used. First, miRNAs were printed to 384-well plates using Hamilton Microlab Star robotics (Hamilton, Reno, NV, USA). Transfection reagent siLentFect (Bio-Rad, Hercules, CA, USA) and OptiMEM were added to plates by Multidrop Combi (Thermo Fisher Scientific, Waltham, MA, USA) and incubated with miRNAs for $1 \mathrm{~h}$ at RT. Next, HeLa H2B-GFP cells were added to plates and incubated for $60 \mathrm{~h}$ after which $100 \mathrm{~nm}$ taxol was introduced to the cells for $12 \mathrm{~h}$. Cells were imaged with ScanR imaging software (Olympus Corporation, Tokyo, Japan), and mitotic index and frequency of cells with multilobed nuclei were recorded.

Pre-miR transfections. Hiperfect (Qiagen, Hilden, Germany) or DharmaFECT (Dharmacon) was used as a transfecting reagent to reverse transfect the cells with Pre-miR miRNA Precursors (Ambion) according to the manufacture's standard protocol. The pre-miR-negative control and pre-miR-378a-5p were used at final concentrations of $40-50 \mathrm{nM}$.

Cell cycle synchronisation. HeLa cells were synchronised to G1/S border by double thymidine block. First, cells were cultured in the presence of thymidine ( $2 \mathrm{~mm}$; Sigma, St Louis, MO, USA) for $16 \mathrm{~h}$, followed by miRNA transfections and culture for $8 \mathrm{~h}$ without thymidine. Then, the second thymidine dose was added to the cells for $48 \mathrm{~h}$ after which cells were released into $\mathrm{S}$ phase by washing three times for $10 \mathrm{~min}$ with culture medium.

Flow cytometry. Harvested cells were resuspended in citrate buffer ( $40 \mathrm{~mm}$ Na-citrate, $0.3 \%$ Triton X-100) with propidium iodide $\left(50 \mu \mathrm{g} \mathrm{ml}^{-1}\right.$; Invitrogen, Life Technologies, Carlsbad, CA, USA) and incubated for $15 \mathrm{~min}$ at RT protected from light. The FACS data were collected using BD FACSCalibur (BD Biosciences, San Jose, CA, USA) and CellQuest Pro software (BD Biosciences) and analysed with the Flowing Software ver. 2.5.1 (Turku Centre for Biotechnology, Turku, Finland, www.flowingsoftware.com).

Image acquisition and analysis. Fixed cells were imaged using a Zeiss inverted 200M microscope (Zeiss GmbH, Jena, Germany) equipped with Hamamatsu ORCA-ER camera (Hamamatsu Photonics, Hamamatsu City, Japan), and Metamorph software version 6.2r6 (Molecular Devices, Downingtown, PA, USA). Kinetochore intensities were quantified from maximum projections created from a $Z$-stack of images acquired with $0.3-0.5 \mu \mathrm{m}$ step interval. For FISH and analysis of nuclear morphology, ScanR imaging system (Olympus Corporation) was used. Live cell imaging was conducted using IncuCyte live-cell imager (Essen Instruments Ltd., Hertfordshire, UK) or a Zeiss inverted $200 \mathrm{M}$ microscope (Zeiss $\mathrm{GmbH}$ ) equipped with an environment chamber, AxioCam MRm camera and AxioVision software (Zeiss $\mathrm{GmbH})$.

Immunofluorescence labelling. Cells on coverslips were fixed in 2\% paraformaldehyde in PHEM buffer containing 0.5\% Triton-X100 for $15 \mathrm{~min}$. For preservation of the microtubules, $0.2 \%$ glutaraldehyde was added to the fixative. Samples were blocked with $20 \%$ boiled normal goat serum for $0.5-1 \mathrm{~h}$ at RT and stained with primary antibodies for $1 \mathrm{~h}$ at RT. Primary antibodies used are listed in the Supplementary Materials. Samples were incubated with Alexa Fluor 488, 555 or 647 secondary antibodies against mouse, rabbit, rat or human antigens (Invitrogen, Life Technologies) for $1 \mathrm{~h}$ at RT and DNA-stained with 4',6-diamidino2-phenylindole (DAPI) before mounting to microscope slides with Vectashield (H-1000; Vector Laboratories, Peterborough, UK).

Immunoblotting. Harvested cells were lysed in $20 \mathrm{~mm}$ Tris- $\mathrm{HCl}$ (pH 7.7), $100 \mathrm{~mm} \mathrm{KCl,} 50 \mathrm{~mm}$ sucrose, $1 \mathrm{~mm} \mathrm{MgCl}_{2}, 0.1 \mathrm{~mm} \mathrm{CaCl}$ and $0.5 \%$ TX-100 (APC-buffer) containing protease inhibitor cocktail (04693132001; Roche, Basel, Switzerland) and phosphatase inhibitor PhosSTOP (4906837001; Roche). For measuring the 
expression of PDGFR- $\beta$ and p-PDGFR- $\beta$, cells were lysed with $\mathrm{NP}-40$ lysis buffer containing 1\% NP-40, $20 \mathrm{~mm}$ Tris- $\mathrm{HCl}$ (pH 8.0), $137 \mathrm{~mm} \mathrm{NaCl}, 10 \%$ glycerol, $2 \mathrm{~nm}$ EDTA, $1 \mathrm{~mm}$ sodium orthovanadate and protease inhibitors (04693132001; Roche). The samples were run on $4 \%-20 \%$ gradient gels. After transfer, membranes were incubated in blocking solution (5\% milk or BSA in TBS) for $1 \mathrm{~h}$, in primary antibody for $0.5-2 \mathrm{~h}$ and in secondary antibody for $1 \mathrm{~h}$ in TBS-T at RT. Primary antibodies used are listed in the Supplementary Materials. IR Dye conjugated anti-mouse 800 and anti-rabbit 800 (Rockland Immunochemicals Inc., Boyertown, PA, USA), and Alexa Fluor anti-mouse 680, anti-rabbit 680 and antigoat 680 (Invitrogen) served as secondary antibodies (all at 1:5000). The signal measurement and the quantitative analysis were done using Odyssey Infrared Imaging System (LI-COR Biotechnology, Lincoln, NE, USA).

RNA isolation and qRT-PCR analysis. RNA was isolated using RNeasy Mini Kit (Qiagen). For c-DNA synthesis, iScript cDNA synthesis kit (Cat. No. 170-8891; Bio-Rad Laboratories Inc.) was used according to the manufacturer's instructions. The Taqman qRT-PCR was performed using Taqman Universal Master Mix II, no PNG (Applied Biosystems, Foster City, CA, USA) and genespecific primers (Sigma) and probes (Roche Universal Probe Library). Primers for qRT-PCR are listed in the Supplementary Materials. The assay readout was done by the Finnish Microarray and Sequencing Centre (Turku Centre for Biotechnology) with the 7900HT Fast Real-Time PCR System (Applied Biosystems). Results were analysed with the comparative Ct method using SDS 2.4 and RQ manager 1.2.1 software (Applied Biosystems) and normalised by comparison with GAPDH expression. MiRVana Total RNA Isolation kit (Ambion) was used to isolate the total RNA from miRNA PCR samples. Taqman MicroRNA Reverse Transcription Kit (Applied Biosystems) and miRNA-specific Taqman MicroRNA Assays (Applied Biosystems) were used to measure miR-378a-5p and $\mathrm{miR}-378 \mathrm{a}-3 \mathrm{p}$ expression after pre-miR-378a-5p transfection. The miRNA expression levels were normalised by comparison with RNU6B.

RTK phosphorylation and kinase phosphorylation array. The effects of miR-378a-5p on phosphorylation of various protein phosphosites were determined with Human Phospho-Kinase Array Kit (Cat. no. ARY003; R\&D Systems, Inc., Minneapolis, MN, USA) and Human Phospho-RTK Array Kit (Cat. no. ARY001; R\&D Systems, Inc.). The arrays were performed according to the manufacturer's instructions. The intensities were quantified using GeneGenius imaging system and GeneTools software version 4.01 (SynGene, Cambridge, UK).

Enzyme-linked immunosorbent assay (ELISA). Cell culture supernatants from HeLa cells transfected with pre-miR-negative control and pre-miR-378a-5p were collected and the total human VEGF-A secreted in the culture medium was measured using Quantikine VEGF-A ELISA kit (R\&D Systems, Inc.) according to the manufacturer's instructions.

Reporter constructs and luciferase assays. A fragment covering the Aurora B 3'UTR region (140 bp) was amplified from the genomic DNA of HeLa cells and the whole Aurora B gene (1224 bp) was amplified from the cDNA of HeLa cells to avoid introns. Specific primers were used (see Supplementary Material). The Aurora B 3'UTR fragment or the fragment covering the whole Aurora B was cloned into SpeI/MluI sites of a pMIR-REPORT Luciferase vector (Ambion). For luciferase assays, HeLa cells were plated $24 \mathrm{~h}$ before transfection and co-transfected with $50 \mathrm{ng}$ of Aurora B 3'UTR or Aurora B reporter plasmid, $50 \mathrm{ng}$ of Renilla luciferase plasmid and $50 \mathrm{~nm}$ of pre-miR construct with Lipofectamine 2000 (Invitrogen). As control, $25 \mathrm{~nm}$ Silencer Firefly Luciferase (GL2 + GL3) siRNA (Ambion) was used. Luciferase activity was determined $24 \mathrm{~h}$ after transfection with a Dual-Glo
Luciferase Assay System (Promega Corporation, Madison, WI, USA) and measured with an EnVision 2100 plate reader (Perkin Elmer Inc., Wellesley, MA, USA).

Fluorescence in situ hybridisation (FISH). The miRNA-transfected HCT-116 cells were trypsinised and swelled for $15 \mathrm{~min}$ using $0.075 \mathrm{M} \mathrm{KCl}$ hypotonic solution. The cells were fixed using methanol/acetic acid $(3: 1)$ for $1 \mathrm{~h}$ at $4{ }^{\circ} \mathrm{C}$. The fixed cells were dropped on clean glass slides and incubated at RT for $10 \mathrm{~min}$. Vysis LSI ETV6(TEL)/RUNX1(AML1) ES Dual colour probe and Vysis LSI 13(13q14) SpectrunGreen probe were purchased from Abbott Inc., Abbott Park, IL, USA. The samples were hybridised according to the manufacturer's instructions. The Image acquisition and analysis was done using ScanR Imaging system (Olympus Corporation). The FITC and Cy3 channels were used to detect green and red signals respectively.

Clinical data analyses. Primary breast carcinoma samples from 101 patients in the MicMa cohort (Naume et al, 2001) were profiled for miRNA expression using the $8 \times 15 \mathrm{k}$ 'Human miRNA Microarray Kit (V2)' with design ID 019118 from Agilent (Agilent Technologies, Santa Clara, CA, USA) following the manufacturer's protocol. Scanning was performed on Agilent Scanner G2565A, signals were extracted using Feature Extraction v9.5 and the subsequent data processing was performed using the GeneSpring software v12.0 (Agilent Technologies). The miRNA signal intensities were $\log _{2}$-transformed and for each sample normalised to the 90th percentile. The miRNAs that were detected in $<10 \%$ of the samples were excluded. The miRNA expression data have been previously published (Enerly et al, 2011) and submitted to the Gene Expression Omnibus (GEO) with accession number GSE19536. The mRNA expression data (published in Enerly et al, 2011, GEO accession number GSE19783) were measured using Agilent $4 \times 44 \mathrm{~K}$ one-colour oligonucleotide arrays (Agilent Technologies). The molecular subtype classification based on mRNA expression was derived using the PAM50 gene list (Parker et al, 2009), the patient clinical information is described in Naume et al (2007) and the Ki67 staining and mitotic index used to group patients into proliferation groups were published in Enerly et al (2011). The proliferation groups were created by dividing samples with a high score on both Ki67 and mitotic index, or high and moderate, into the high proliferative group (24 samples), and the samples that scored low/negative on both $\mathrm{Ki} 67$ and mitotic index, or low and moderate, into the low proliferation group (35 samples) (Enerly et al, 2011).

Statistical analysis. Statistical analysis was performed using twotailed Student's $t$-test. In analysis of the FISH results, $\chi^{2}$ test was used. To evaluate differences in miRNA expression among clinical data groups, the Wilcoxon rank-sum test was applied.

\section{RESULTS}

Excess miR-378a-5p perturbs normal mitosis. The miR-378a-5p was identified as a potent mitosis perturbing miRNA in a cellbased screen of 810 human pre-miRNAs. In the presence of taxol, excess miR-378a-5p significantly decreased mitotic index (MI) and resulted in formation of HeLa cells with multilobed nuclei (MNs). In drug-free culture conditions, excess miR-378a-5p caused an increase of cells with large intact nuclei in comparison with the non-targeting control miRNA (Figure 1A). As expected, transfection of HeLa cells with pre-miR-378a-5p significantly elevated only the levels of miR-378a-5p without altering the levels of miR-378a$3 p$ located in the same pre-miRNA hairpin loop structure (Figure $1 \mathrm{~B}$ and $\mathrm{C}$ ). To validate miR-378a-5p-induced cell cycle effects, we time-lapsed filmed synchronised HeLa cell populations overexpressing miR-378a-5p or control miRNA. In drug-free 
A
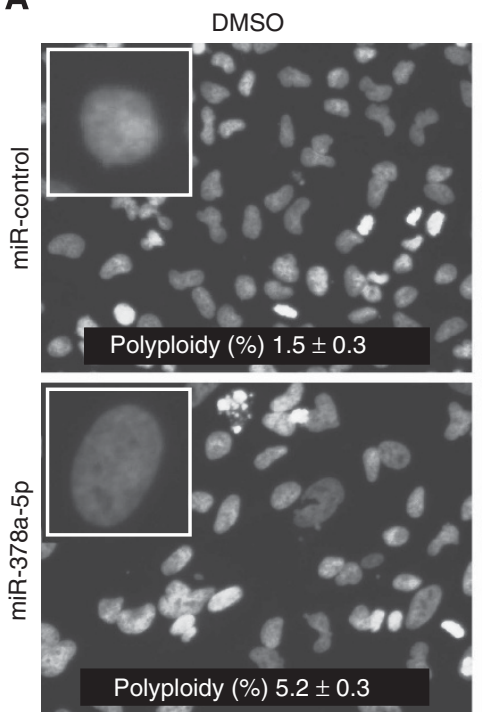
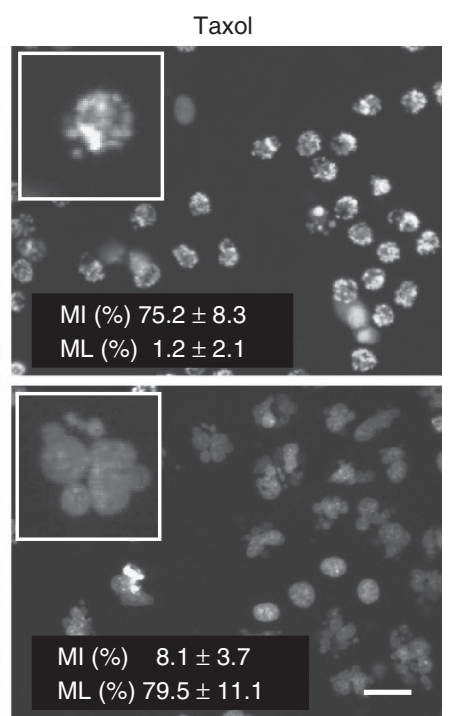

B

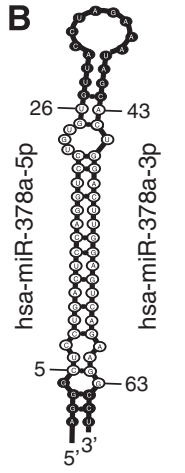

C

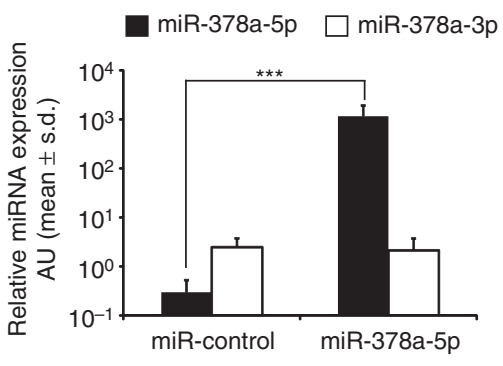

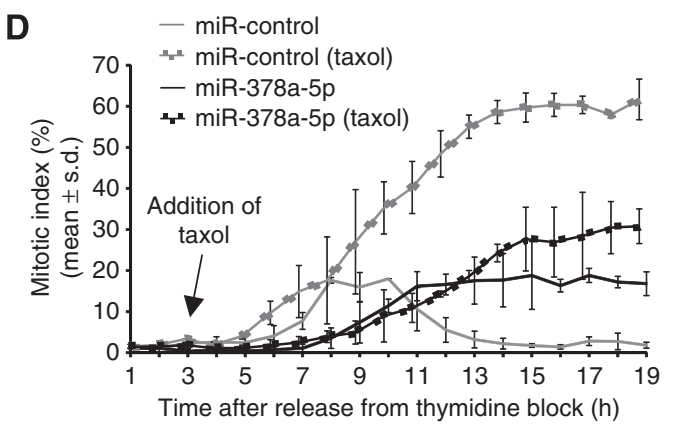
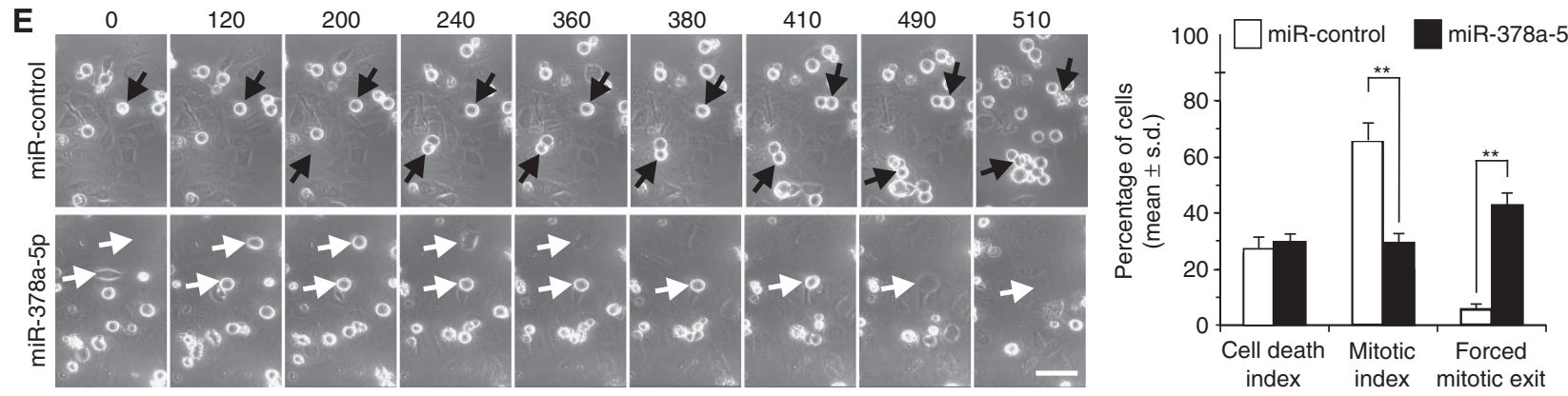

In the presence of taxol

\section{F}

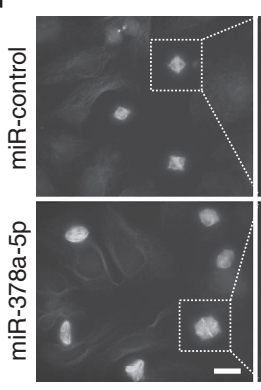

$\alpha$-tubulin

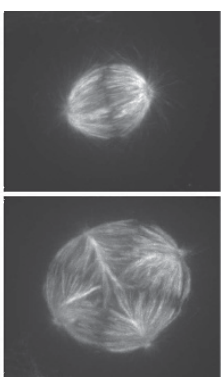

Pericentrin

DNA
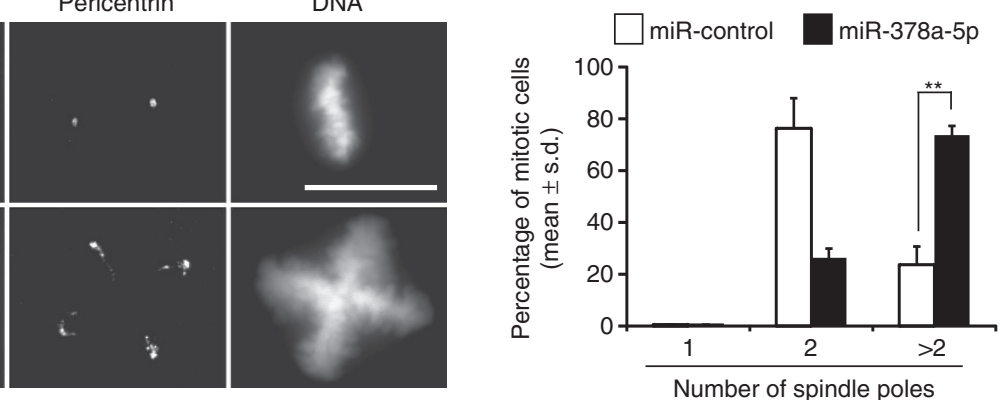

Figure 1. Excess of miR-378a-5p causes pleiotropic mitotic anomalies. (A) Representative micrographs from the HTS for mitosis perturbing miRNAs. In the DMSO-treated HeLa cell populations, overexpression of miR-378a-5p increases the frequency of polyploid cells compared with miR-control. In the taxol-treated HeLa cells, excess of miR-378a-5p decreases the mitotic index (MI) and elevates the frequency of cells with multilobed nuclei (MLs). (B) The structure of the miR-378 hairpin loop. (C) Relative amounts of miR-378a-5p and miR-378a-3p in HeLa cell populations at $36 \mathrm{~h}$ post transfection with miR-control or miR-378a-5p. (D) Mitotic indices in synchronised HeLa cell populations transfected with miR-control or miR-378a-5p. (E) Representative still images from time-lapse films showing miR-control- or miR-378a-5p-transfected HeLa cells undergoing mitosis in the presence of taxol; control cells (black arrows) arrest to $M$ phase for at least $7 \mathrm{~h}$, whereas miR-378a-5p-overexpressing cells (white arrows) undergo a forced mitotic exit. The numbers indicate time in min. The graph illustrates the quantification of different cell fates in synchronised HeLa cell populations overexpressing miR-control or miR-378a-5p. (F) Representative micrographs showing induction of multipolarity by miR-378a-5p overexpression. The graph shows quantification of multipolarity in the indicated cell populations. Data are mean \pm s.d. from three replicate assays. The asterisks denote statistical significances ( $\left.{ }^{\star \star} P<0.01,{ }^{\star \star \star} P<0.001\right)$. The scale bar $=20 \mu \mathrm{m}(\mathbf{A}$ and $\mathbf{F})$ and $50 \mu \mathrm{m}(\mathbf{E})$. Abbreviation: $\mathrm{AU}=$ arbitrary units.

culture conditions, cell populations with excess miR-378a-5p exhibited a short pre-mitotic delay of ca. $4 \mathrm{~h}$ in comparison with controls (Figure 1D). After entry into $M$ phase, miR-378a-5p- overexpressing cells maintained an average MI of $\sim 18 \%$ for at least $9 \mathrm{~h}$, indicating a transient mitotic arrest of individual cells (Figure 1D). In the presence of taxol, the control cell populations 
arrested at $\mathrm{M}$ phase as expected (an average MI of over $50 \%$ was maintained for at least $7 \mathrm{~h}$ ), whereas the miR-378a-5p-overexpressing cell populations underwent forced mitotic exit after a transient arrest (Figure 1D and E, Supplementary Movies 1 and 2). The perturbation of mitosis by miR-378a-5p was confirmed using FACS and single-cell analysis of miR-378a-5p- or control miRNAtransfected HeLa cells (Supplementary Figure S1). Transfection of HeLa cells with anti-miR-378a-5p did not cause any apparent cell cycle disturbances (data not shown). Moreover, HeLa cell populations co-transfected with anti-miR-378a-5p and miR-378a$5 \mathrm{p}$ displayed comparable rates of cells with large nuclei and exhibited similar mitotic delay in drug-free culture conditions as the miR-378a-5p-overexpressing cells (data not shown).

Analysis of the spindle structure revealed that a larger percentage of mitotic cells in the miR-378a-5p-transfected cell population exhibited more than two pericentrin-positive foci in comparison with cells transfected with control miRNA; at $72 \mathrm{~h}$ post transfection, the percentage of mitotic cells with $>2$ foci was $73.7 \pm 3.5 \%$ and $23.0 \pm 7.1 \%$ in the miR-378a-5p- and miR-controltransfected cell populations respectively $(P<0.01$, Figure $1 \mathrm{~F})$. We conclude that excess miR-378a-5p induces pleiotropic cell division anomalies that include multipolarity, polyploidy, transient mitotic delay and override of taxol block.

High miR-378a-5p levels increase VEGF-A production and activate the RTK-MAPK pathway in cells. Earlier work has implicated miR-378a-5p in upregulation of angiogenic growth factor VEGF-A (Hua et al, 2006). In line with this, we found that VEGF-A mRNA in cells and protein levels in the culture medium are significantly increased by miR-378a-5p compared with controls (Figure 2A). Analysis of receptor tyrosine kinases (RTKs) indicated a notable increase in the phosphorylation status of PDGFR- $\beta$, ErbB2, EphRA7 and VEGFR-2 by excess miR-378a-5p (Figure 2B), consistent with the published data showing that VEGF-A can stimulate all four RTKs (Ball et al, 2007). Western blotting confirmed the dot blot results for increased phosphorylation (Tyr857) of PDGFR- $\beta$ that was expressed in sufficiently high quantities in HeLa cells to enable detection (Figure 2B). The VEGFR-2 was not detectable with blotting in HeLa cells (data not shown). As the four RTKs can trigger multiple signalling cascades, we next investigated the impact of miR-378a-5p overexpression on 46 cell cycle kinases using a human phospho-kinase array. Surprisingly, only the phosphorylation status of ERK1/2 (Thr202/Tyr204 and Thr185/ Tyr187) was markedly elevated in cells with excess miR-378a-5p in comparison with controls (Figure 2C). This was further validated using western blotting that indicated a notable increase of phosphoERK1/2 (Thr202/Tyr204) but no change in total ERK1/2 levels by miR-378a-5p overexpression (Figure $2 \mathrm{C}$ ). These results are in line with earlier studies reporting that excess miR-378a-5p elevates VEGF-A (Hua et al, 2006) and the well-validated notion that VEGFA stimulates ERK1/2 phosphorylation.

The finding that excess miR-378a-5p triggers ERK1/2 prompted us to test whether kinase inhibition can restore the normal mitosis in miR-378a-5p-transfected cells. The HeLa cells overexpressing control miRNA or miR-378a-5p were treated with DMSO or $25 \mu \mathrm{M}$ FR180204, an ATP-competitive inhibitor of ERK1/2, at $24 \mathrm{~h}$ post transfection and were time-lapse filmed for $24 \mathrm{~h}$ before fixation and DNA staining. Quantification of the time-lapse recordings and fixed cell samples indicated partial rescue from miR-378a-5pinduced mitotic anomaly effects upon ERK1/2 inhibition; duration of mitosis, frequency of M-phase exit without cytokinesis and number of cells with large nuclei were reduced closer to the control values in the presence of FR180204 (Figure 2D). When the assay was performed in the presence of taxol, inhibition of ERK1/2 significantly $(P<0.05)$ suppressed the miR-378a-5p-induced SAC override (Figure 2D). From this, we summarise that overexpression of miR-378a-5p stimulates VEGF-A production that causes activation of the RTK-MAPK cascade culminating to elevated phosphorylation of ERK1/2 kinase. Chemical suppression of ERK1/2 can partially restore normal mitosis in cells with excess miR-378a-5p.

Excess miR-378a-5p suppresses Aurora B mRNA and protein levels and perturbs integrity of the $\mathrm{CPC}$. The result that miR$378 \mathrm{a}-5 \mathrm{p}$ overexpression overrides taxol-induced M-phase block pointed us to examine the impact of the miRNA on Aurora B kinase that is essential for the maintenance of SAC-dependent mitotic arrest in response to spindle and chromosomal defects (Musacchio, 2011). Cycling and mitotically arrested HeLa cell populations overexpressing miR-378a-5p exhibited significantly $(P<0.01)$ reduced Aurora $\mathrm{B}$ mRNA and protein levels when compared with control miRNA (Figure $3 \mathrm{~A}$ and $\mathrm{B}$ ). Moreover, a dramatic reduction was observed in the centromere association of the kinase as well as in the signal intensity of pCenp-A (Ser 7) labelling $(P<0.001$, Figure $3 \mathrm{C})$, a marker for Aurora B kinase activity (Zeitlin et al, 2001). As expected, tight interdependency of the CPC subunits (Honda et al, 2003) led to significant loss of centromere-bound survivin (reduced by $54.3 \pm 32.1 \%$ ) and INCENP (reduced by $59.9 \pm 30.5 \%$ ) upon Aurora B perturbation by excess miR-378a-5p compared with controls $(P<0.001$, Supplementary Figure S2). Despite the fact that $A U R K B$ is not a predicted target gene of miR-378a-5p, we cloned AURKB $3^{\prime} \mathrm{UTR}$ and the full gene sequence, including both $5^{\prime}$ and $3^{\prime}$ UTRs, downstream of a firefly luciferase reporter gene and co-transfected the reporter constructs with either control miRNA or miR-378a-5p into HeLa cells. No repression of luciferase activity was observed by miR-378a-5p in comparison with control (Figure 3D). Our attempts to rescue miR-378a-5p-induced mitotic disturbances using exogenous overexpression of Aurora B failed because of high cytotoxicity of the expression vector (data not shown). In the surviving cells, Aurora B overexpression phenotype overlapped with that induced by excess miR-378a-5p (multipolarity and polyploidy) that hampered analysis of the remaining cells. However, treatment of miR-378a-5p-overexpressing HeLa cells with ERK1/2 inhibitor FR180204 partially rescued Aurora B protein levels in comparison with control (Figure 3E). Taken together, these results indicate that excess of miR-378a-5p indirectly diminishes Aurora B levels via a route that involves ERK1/2.

High miR-378a-5p expression in cells is associated with elevated frequency of chromosome missegregation. Earlier work has demonstrated formation of cells with large multilobed nuclei and micronuclei after Aurora B RNAi in cell culture (Hauf et al, 2003). Moreover, the frequency of cells with syntelic chromosome attachments that can contribute to aneuploidy via lagging chromatids is increased upon inhibition of Aurora B activity (Hauf et al, 2003). As miR-378a-5p overexpression had a strong suppressive impact on the Aurora B kinase activity, we further tested whether excess miR-378a-5p causes numerical chromosome anomalies in a near-diploid human HCT-116 colorectal cancer cell line (Lengauer et al, 1997). The HCT-116 cells responded to miR$378 \mathrm{a}-5 \mathrm{p}$ overexpression similarly to HeLa cells; they became polyploid and exhibited reduced Aurora B protein levels (Supplementary Figure S3). Analysis of the chromosome 12, 13 and 21 copy numbers at $\sim 65 \mathrm{~h}$ post transfection using FISH probes revealed significant increase in the chromosome number between miR-378a-5p- and control miRNA-overexpressing HCT116 cell populations $(P<0.001$, Figure 4$)$. Null and monosomy were less frequent events in both the controls and miR-378a-5poverexpressing HCT-116 cells (Figure 4). In summary, excess miR$378 \mathrm{a}-5 \mathrm{p}$ leads to downregulation of Aurora B and induces mitotic defects that give rise to numerical chromosome anomalies such as trisomy and tetrasomy in a colon cancer cell line. 
A
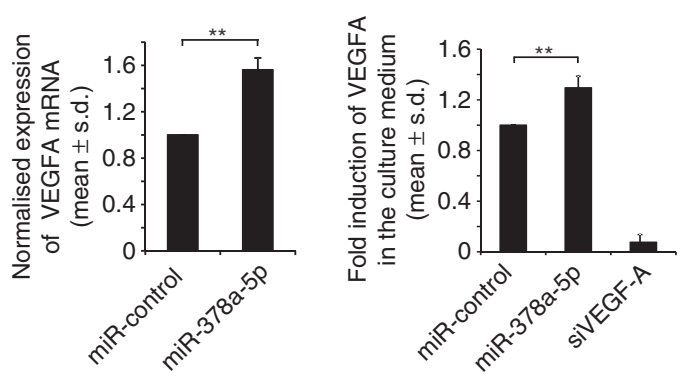

\section{C}
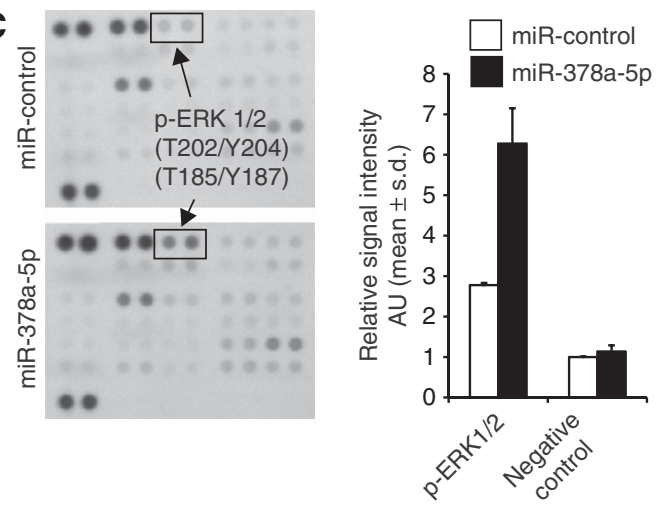

B
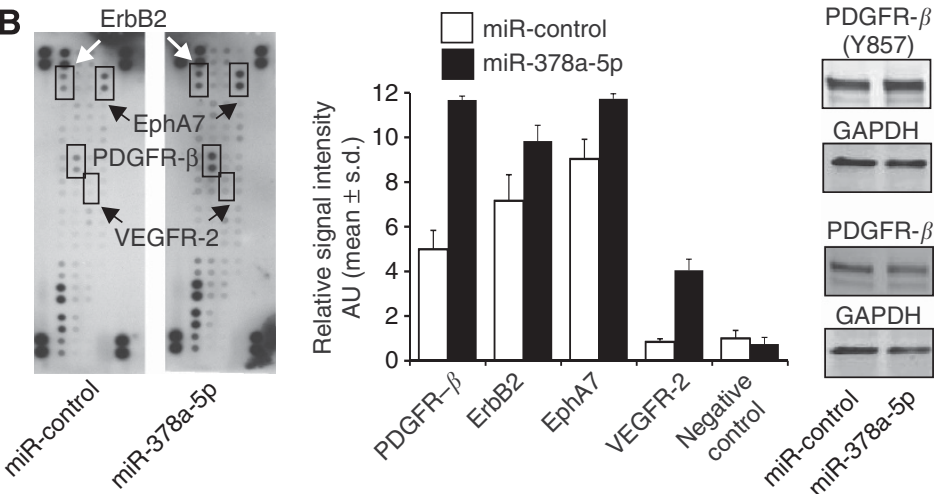
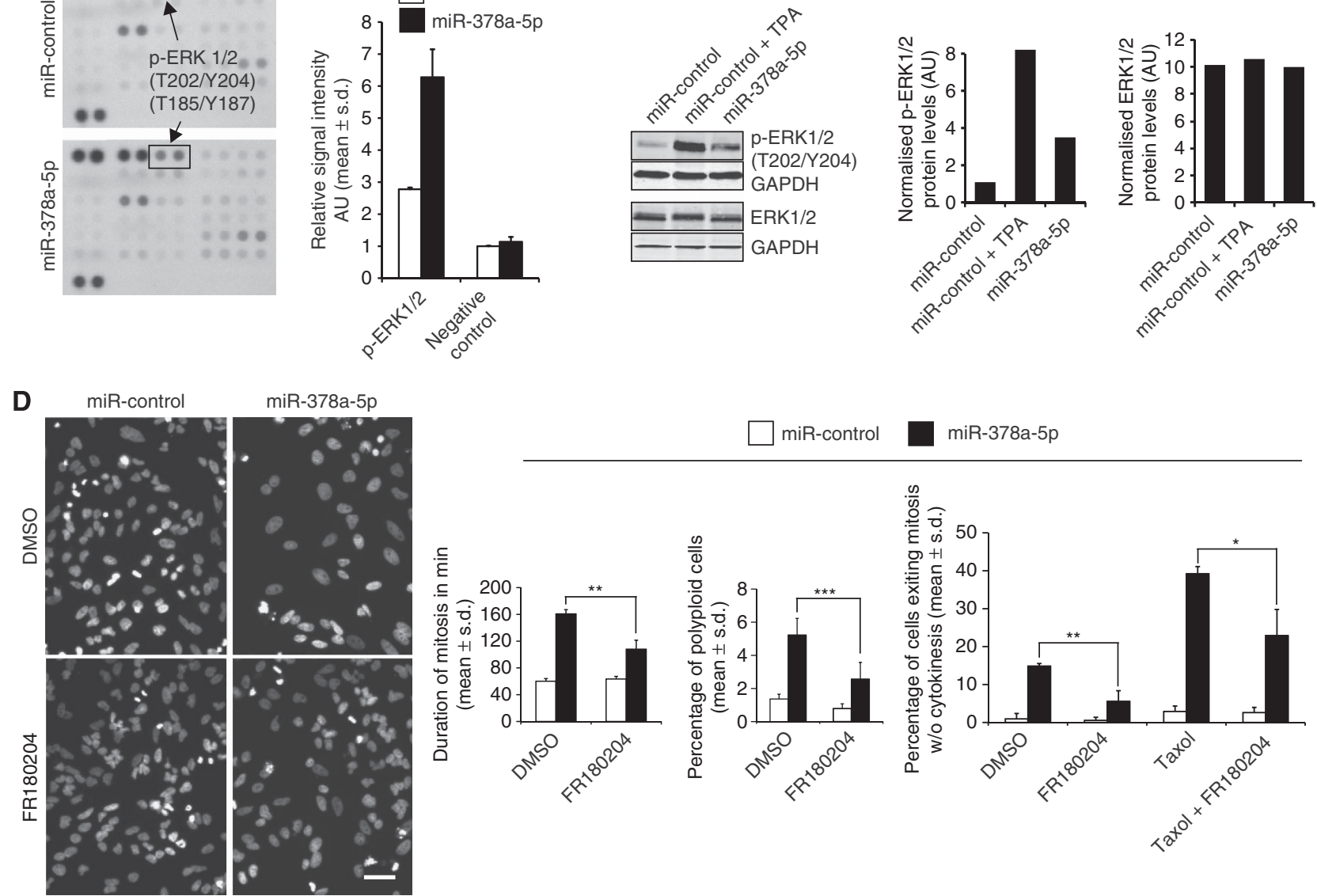

miR-control

miR-378a-5p
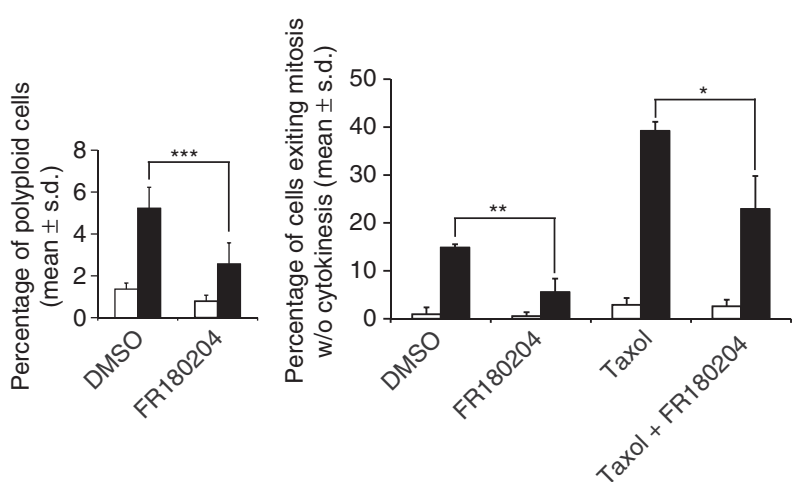

Figure 2. Excess of miR-378a-5p increases VEGF-A production and activates the RTK-MAPK pathway. (A) The mRNA and protein levels of VEGF-A are significantly increased by miR-378a-5p in HeLa cells and in culture medium analysed at $72 \mathrm{~h}$ post transfection, respectively. (B) Human phospho-RTK dot blot array indicating elevated phosphorylation of PDGFR- $\beta$, ErbB2, EphRA7 and VEGFR-2 by miR-378a-5p. The graph shows quantification of the dot blot signal intensities. The results were confirmed using western blotting for phosphorylated (Y857) and non-phosphorylated PDGF-R 3 . (C) Excess miR-378a-5p increases phosphorylation of ERK1/2 (T202/Y204) without affecting total protein levels. The graphs show quantification of the phosphokinase dot blot and pERK1/2 antibody western blotting signals. The TPA was used to stimulate ERK activation in the miR-control cells. (D) Inhibition of ERK1/2 with FR180204 partially rescues from the miR-378a-5p-induced anti-mitotic phenotype. Representative micrographs showing lowered frequency of polyploidy by miR-378a-5p upon ERK1/2 inhibition. The graphs show quantifications of mitotic duration and frequency of polyploidy and forced mitotic exit in the cell populations after indicated treatments. Data are mean \pm s.d. from three replicate assays $(\mathbf{A}$ and $\mathbf{D})$. The asterisks denote statistical significances ( ${ }^{\star} P<0.05,{ }^{\star \star} P<0.01,{ }^{\star \star \star} P<0.001$ ). The scale bar $(\mathbf{D})=50 \mu \mathrm{m}$. Abbreviation: $\mathrm{AU}=$ arbitrary units.

High expression of miR-378a-5p and PPARGC1B correlates with tumour grade, ER status and markers of increased proliferation in breast cancer. To gain insight into the in vivo relevance of miR-378a-5p, miRNA expression in breast tumours was compared with clinical and molecular parameters. Separating the tumours into histological grade showed that miR-378a-5p expression was significantly increased with increasing grade $(P=0.03$ when comparing grades 1 and 3 , and $P=0.01$ when comparing grades 2 and 3; Figure 5A), suggesting that miR-378a$5 \mathrm{p}$ is more highly expressed in less differentiated tumours. In breast cancer, five molecular subtypes with prognostic impact have been established based on gene expression patterns, of which luminal $\mathrm{A} / \mathrm{B}$ and basal-like tumours have the most reciprocal gene expression profiles as well as major differences in clinical parameters, including survival (Perou et al, 2000; Sorlie et al, 2001; Naume et al, 2007). Assessing miR-378a-5p expression 
A

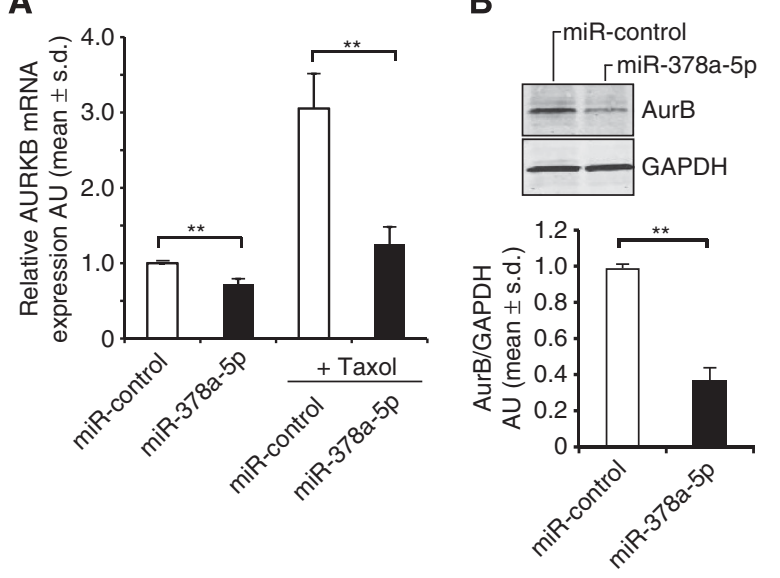

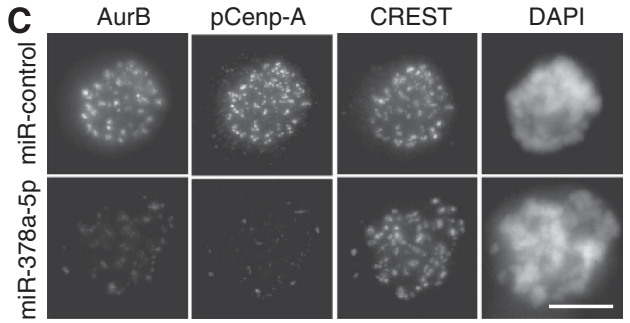

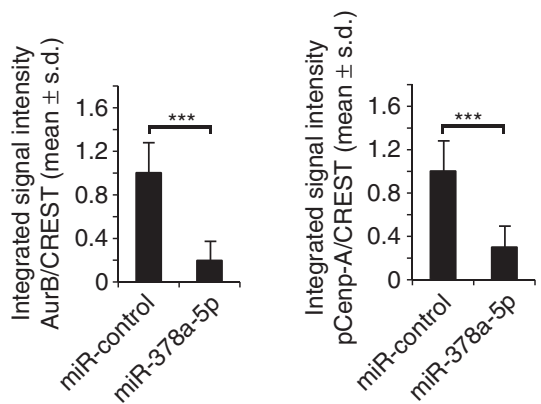

E

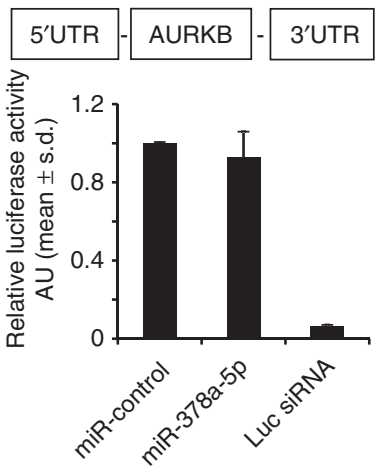

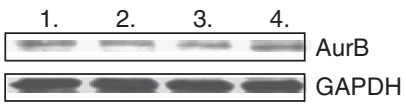

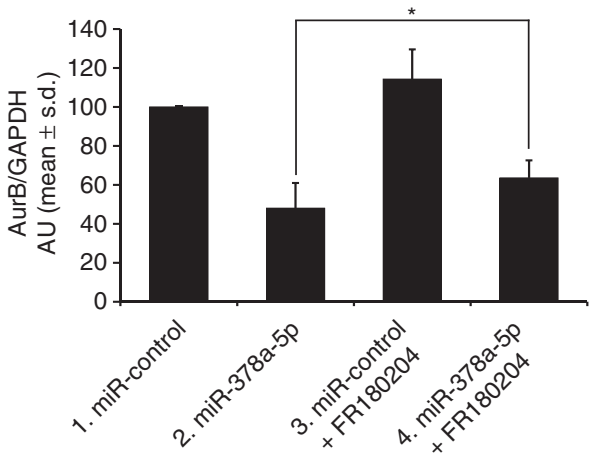

Figure 3. Excess of miR-378a-5p indirectly suppresses Aurora B during mitosis. Aurora B kinase mRNA (A) and protein (B) levels are significantly reduced by miR-378a-5p overexpression in HeLa cells (data are mean \pm s.d. from three replicate assays). (C) Representative micrographs showing loss of Cenp-A phosphorylation (Ser7) and Aurora B immunofluorescence signals in taxol-arrested miR-378a-5p-overexpressing cells in comparison with controls. CREST marks the centromeres. The graphs show quantification of the pCenp-A and Aurora B centromere signals normalised against CREST. The data are mean \pm s.d. from 30 cells, 20 centromeres quantified per cell. (D) The graphs show quantification of luciferase reporter assays indicating that miR-378a-5p does not bind to the $3^{\prime}$ UTR or elsewhere of the Aurora B mRNA. Luciferase silencing was used as a positive control. Data are mean \pm s.d. from 4 to 5 replicate assays. (E) The Western blot and graph shows partial recovery of Aurora B protein levels in FR180204treated HeLa cells with excess of miR-378a-5p in comparison with controls. Data are mean \pm s.d. from 3 to 5 replicate assays. The asterisks denote statistical significances ( $\left.{ }^{\star} P<0.05,{ }^{\star \star} P<0.01,{ }^{\star \star \star} P<0.001\right)$. The scale bar $(\mathbf{C})=10 \mu \mathrm{m}$. Abbreviation: $\mathrm{AU}=$ arbitrary units.

within these subtypes revealed differential expression between the subtypes $(P<0.001)$ with higher miR-378a-5p expression in basallike tumours compared with luminal $\mathrm{A}$ and luminal $\mathrm{B}$ tumours (Figure 5B). Dividing the tumours according to oestrogen receptor alpha (ER) status, which is a well-established prognostic and predictive marker in breast cancer, showed significant increased miR-378a-5p expression in ER negative compared with ER positive samples $(P<0.001$, Figure $5 \mathrm{C})$. Furthermore, when dividing the tumours into a high and a low proliferation group based on expression of the proliferation marker Ki67 and mitotic index, miR-378a-5p was more highly expressed in tumours of the high proliferation group compared with tumours in the low proliferation group $(P<0.001$, Figure 5D). However, no direct association was observed between high miR-378a-5p expression and tri- and tetra-ploidy in these tumours (data not shown). Similar findings were also observed when we analysed another data set with $\sim 1300$ tumour samples (data not shown, METABRIC; Dvinge et al, 2013). Interestingly, the same association to grade, molecular subtype, ER and proliferation group was recapitulated when considering the expression of the miR-378a-5p host gene, PPARGC1B, within the same breast tumours (Supplementary Figure S4).

\section{DISCUSSION}

Earlier reports propose that miR-378a-5p can contribute to breast tumourigenesis by promoting angiogenesis (Lee et al, 2007) and via targeting energy metabolism genes ERR $\gamma$ and GABPA (Eichner et al, 2010). We identified miR-378a-5p as a potent mitosis perturbing element that impairs fidelity of cell division and reduces taxol sensitivity in cell culture when overexpressed. Our study confirms the earlier observation that excess miR-378a-5p upregulates VEGF-A (Hua et al, 2006) that we found to increase phosphorylation of PDGFR- $\beta$, ErbB2/HER2, EphA7 and VEGFR-2. In agreement with studies showing that VEGF-A triggers PDGFR$\beta$, VEGFR-2 and ErbB2 signalling that can modulate the MAPK pathway (Pinkas-Kramarski et al, 1998; Jurek et al, 2011), excess miR-378-a-5p resulted in elevated phosphorylation of ERK1/2 and, 

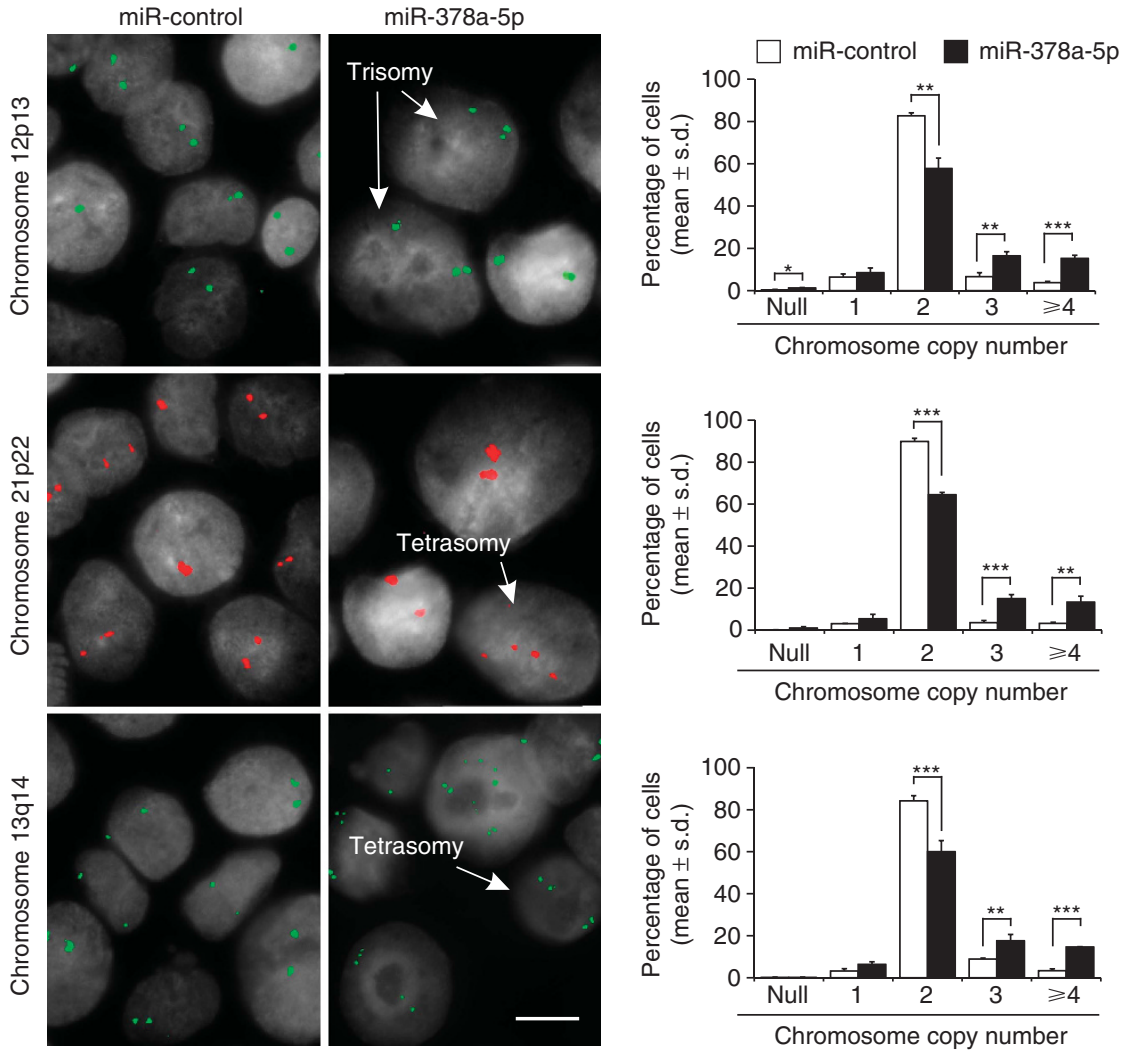

Chromosome copy number
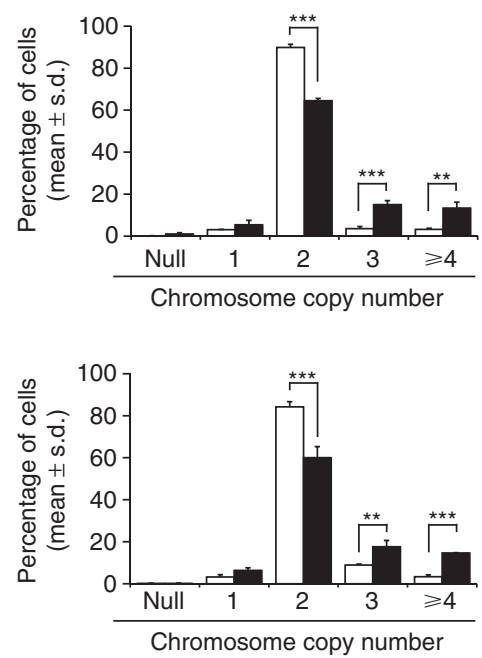

Figure 4. Chromosome copy number is altered in miR-378a-5p-overexpressing HCT-116 cells. Representative micrographs showing miR-control- and miR-378a-5p-transfected cells (arrows) in which the copy number of chromosomes 12, 13 or 21 is changed. The scale $\mathrm{bar}=10 \mu \mathrm{m}$. The graphs show quantification of the copy number variation within a pool of 800-1200 cells for both miR-control and miR-378a-5p. Data are mean \pm s.d. from 2 to 3 replicate assays per probe. The asterisks denote statistical significances $\left({ }^{\star} P<0.05,{ }^{\star \star} P<0.01,{ }^{\star \star \star} P<0.001\right)$.
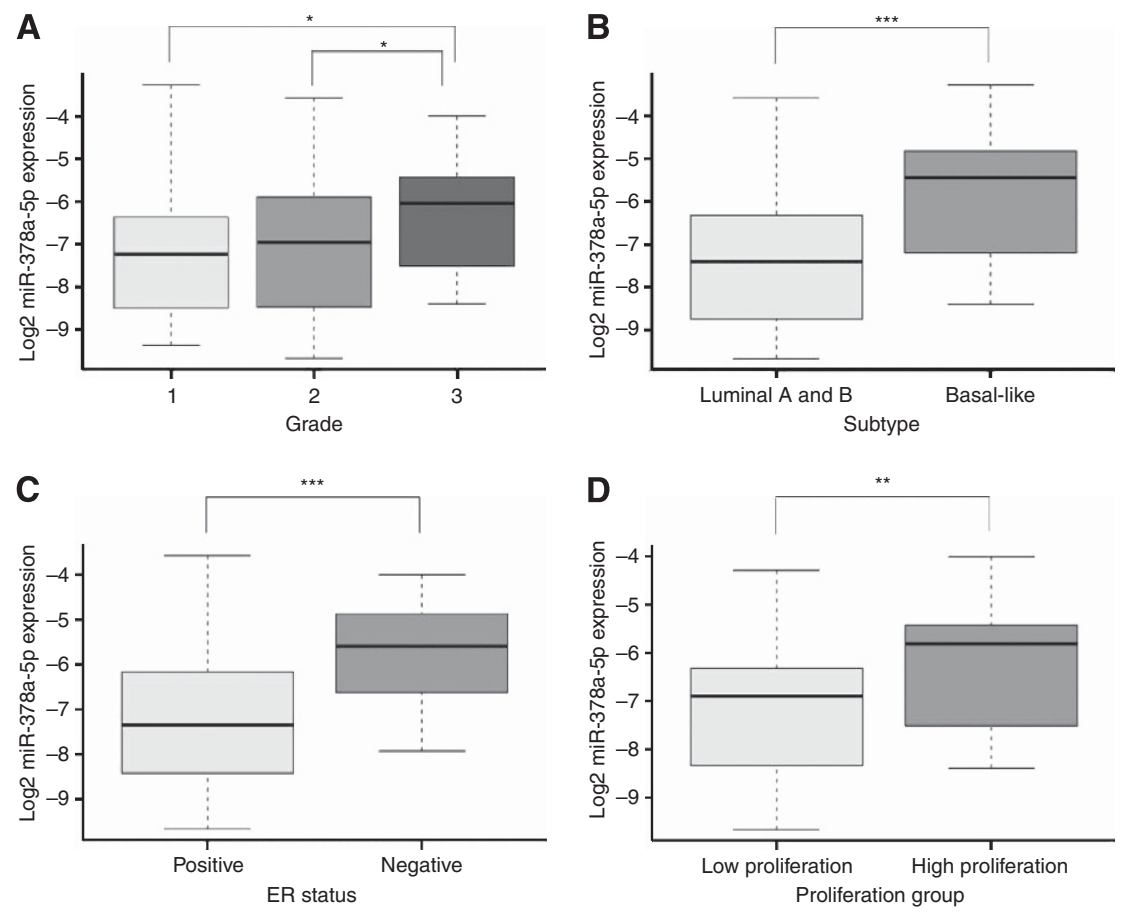

Figure 5. Boxplots showing the association of miR-378a-5p expression to clinical and molecular subgroups of breast cancer patients ( $n=101)$. (A) The miR-378a-5p expression in tumours of different grades (1, 2 and 3). (B) The miR-378a-5p expression in the luminal and basal-like molecular subtypes of breast cancer. (C) The miR-378a-5p expression in oestrogen receptor (ER)-positive and -negative tumours. (D) The miR-378a-5p expression in tumours belonging to high and low proliferation groups based on the combined assessment of Ki67 expression and mitotic index. The asterisks denote statistical significances $\left({ }^{\star} P<0.05\right.$, $\left.{ }^{\star \star} P<0.01,{ }^{\star \star \star} P<0.001\right)$. 
surprisingly, depletion of Aurora B kinase. Loss of Aurora B provides a plausible mechanistic explanation for the observed mitotic anomalies and taxol insensitivity of miR-378a-5p-overexpressing cells. Depletion of the kinase by RNAi or functional perturbation using neutralising antibodies has been reported to override microtubule drug-imposed $\mathrm{M}$-phase arrest and cause polyploidisation due to loss of essential Aurora B functions in the maintenance of SAC signalling and cytokinesis, respectively (Kallio et al, 2002; Ditchfield et al, 2003; Hauf et al, 2003). The observed loss of centromere-bound INCENP and survivin in miR-378a-5poverexpressing cells is likely a consequence of Aurora B depletion causing collapse of the CPC that is known to be tightly dependent on its core subunit interactions (Honda et al, 2003). The high cytotoxicity of Aurora B overexpression prevented us from rescuing the excess miR-378a-5p-induced mitotic defects by elevated kinase levels, leaving a possibility that other mitotic targets of miR-378a-5p can contribute to the premature SAC inactivation.

Interestingly, the cellular impact of miR-378a-5p overexpression resembles closely the RNAi phenotype of Raf kinase inhibitory protein (RKIP) that is reported to cause upregulation of Raf-1/ MEK/ERK cascade, suppression of Aurora B kinase activity and insensitivity of cells to taxol treatment (Eves et al, 2006; al-Mulla et al, 2011). Interestingly, the Aurora B mRNA levels were also reduced upon RKIP depletion (al-Mulla et al, 2011). However, the mechanism by which the RKIP-ERK axis regulates Aurora B kinase activity has remained unknown. In our study, Aurora B was not found to be a direct target of miR-378a-5p, even though mRNA levels of the kinase were depleted by excess miR-378a-5p. Therefore, we speculate that the impact of miR-378a-5p on Aurora $\mathrm{B}$ is mediated via a transcription factor regulating the $A U R K B$ expression, Forkhead box protein M1 (FOXM1) being a possible candidate (Wang et al, 2005). The ERK1/2 may negatively modulate this process as its inhibition partially rescued the Aurora $B$ levels in the miR-378a-5p-overexpressing cells. However, the detailed molecular mechanism between the loss of Aurora B and increased amplitude of ERK signalling in the miR-378a-5poverexpressing cells remains to be determined.

At the cellular level, excess miR-378a-5p increased chromosome tri- and tetrasomy in the chromosomally stable HCT-116 cells that can be linked to altered Aurora B activity known to induce CIN and aneuploidy (Ota et al, 2002; Hauf et al, 2003; Hontz et al, 2007; Honma et al, 2013). In vivo, we found that high expression of miR$378 \mathrm{a}-5 \mathrm{p}$ and its host gene PPARGC1B showed significant correlation with clinicopathological markers of breast cancer. The expression of miR-378a-5p was increased in higher-grade tumours and the basal-like subtype. Tumours of the basal-like subtype are generally described as high-grade ductal carcinomas and they have been associated with a more aggressive disease and poorer survival (Valentin et al, 2012). They lack the expression of hormone receptors ER and $\mathrm{PR}$, as well as the amplification of the $E R B B 2$ gene. Accordingly, miR-378a-5p expression was higher in ER-negative tumours and was associated with tumours with high proliferation. We did not, however, find significant correlation between high miR-378a-5p levels and increased tri- and tetraploidy in these breast tumours. This can reflect association of the increased miRNA expression with cell proliferation. Alternatively, the possible correlation can be masked by the biologically complex tumour phenotypes in which deregulation of miR-378a-5p may be causally implicated in some but not all cases. Generally, our findings are in line with a study by Eichner et al (2010) showing that miR-378a-5p expression increases during breast cancer progression. Similar associations with grade, molecular subtype and proliferation were observed for the host gene PPARGC1B within our patient cohort. This is in concordance with previous findings showing that miRNAs are often expressed in coordination with their host gene mRNA (Rodriguez et al, 2004; Baskerville and Bartel, 2005).
Together, our results and published data propose that elevated miR-378a-5p expression may contribute to tumourigenesis via multiple pathways; increased neovascularisation (Lee et al, 2007) can accelerate tumour growth, shift from oxidative to glycolytic metabolism (Eichner et al, 2010) can make tumour cells less dependent on oxidative phosphorylation as their energy supply, and our observation of elevated aneuploidy can support malignant cell behaviour. The tumour cells may utilise excess miR-378a-5p to fine-tune gene dosage (e.g., $A U R K B$ ) to achieve selection advantage. Moreover, our data point to a possibility that elevated rates of miR-378a-5p may antagonise cellular effects of taxanes that still are one of the first-line adjuvant chemotherapy forms in the treatment of breast cancer. The data raise an intriguing question of whether assessment of miR-378a-5p expression levels in the patients' tumour cells or body fluids possesses clinical value in terms of tumour grading and/or prediction of drug response. The first patient studies have shown encouraging results for the analysis of miR-378a-5p serum levels as biomarker for detection of gastric cancer (Liu et al, 2012), although for renal cell carcinoma the prognostic value of circulating miR-378a-5p remains controversial (Hauser et al, 2012; Redova et al, 2012).

\section{ACKNOWLEDGEMENTS}

This work was supported by the Academy of Finland (Grant Numbers 138204 and 137468), the Finnish Cancer Organizations, the Finnish Cultural Foundation, the K.G. Jebsen Centre for Breast Cancer Research, South-Eastern Norway Regional Health Authority (Grant Number 2011042) and the Norwegian Cancer Society (Grant Number 138296-PR-2008-0108). P Toivonen is acknowledged for technical help in HTS and E Narvi for cloning instructions. We thank E Nigg for providing the INCENP antibody and G Gorbsky for critical reading of the manuscript.

\section{REFERENCES}

al-Mulla F, Bitar MS, Taqi Z, Rath O, Kolch W (2011) RAF kinase inhibitory protein (RKIP) modulates cell cycle kinetics and motility. Mol Biosyst 7: 928-941.

Ball SG, Shuttleworth CA, Kielty CM (2007) Vascular endothelial growth factor can signal through platelet-derived growth factor receptors. J Cell Biol 177: 489-500.

Baskerville S, Bartel DP (2005) Microarray profiling of microRNAs reveals frequent coexpression with neighboring miRNAs and host genes. RNA 11: 241-247.

Blower PE, Chung JH, Verducci JS, Lin S, Park JK, Dai Z, Liu CG, Schmittgen TD, Reinhold WC, Croce CM, Weinstein JN, Sadee W (2008) MicroRNAs modulate the chemosensitivity of tumor cells. Mol Cancer Ther 7: 1-9.

Carter SL, Eklund AC, Kohane IS, Harris LN, Szallasi Z (2006) A signature of chromosomal instability inferred from gene expression profiles predicts clinical outcome in multiple human cancers. Nat Genet 38: 1043-1048.

Ditchfield C, Johnson VL, Tighe A, Ellston R, Haworth C, Johnson T, Mortlock A, Keen N, Taylor SS (2003) Aurora B couples chromosome alignment with anaphase by targeting BubR1, Mad2, and Cenp-E to kinetochores. J Cell Biol 161: 267-280.

Dobles M, Liberal V, Scott ML, Benezra R, Sorger PK (2000) Chromosome missegregation and apoptosis in mice lacking the mitotic checkpoint protein Mad2. Cell 101: 635-645.

Dvinge H, Git A, Graf S, Salmon-Divon M, Curtis C, Sottoriva A, Zhao Y, Hirst M, Armisen J, Miska EA, Chin SF, Provenzano E, Turashvili G, Green A, Ellis I, Aparicio S, Caldas C (2013) The shaping and functional consequences of the microRNA landscape in breast cancer. Nature 497: 378-382.

Eichner LJ, Perry MC, Dufour CR, Bertos N, Park M, St-Pierre J, Giguere V (2010) miR-378( $\left.{ }^{*}\right)$ mediates metabolic shift in breast cancer cells via the PGC-1beta/ERRgamma transcriptional pathway. Cell Metab 12: 352-361. 
Enerly E, Steinfeld I, Kleivi K, Leivonen SK, Aure MR, Russnes HG, Ronneberg JA, Johnsen H, Navon R, Rodland E, Makela R, Naume B, Perala M, Kallioniemi O, Kristensen VN, Yakhini Z, Borresen-Dale AL (2011) miRNA-mRNA integrated analysis reveals roles for miRNAs in primary breast tumors. PLoS One 6: e16915.

Eves EM, Shapiro P, Naik K, Klein UR, Trakul N, Rosner MR (2006) Raf kinase inhibitory protein regulates aurora $\mathrm{B}$ kinase and the spindle checkpoint. Mol Cell 23: 561-574.

Hauf S, Cole RW, LaTerra S, Zimmer C, Schnapp G, Walter R, Heckel A, van Meel J, Rieder CL, Peters JM (2003) The small molecule Hesperadin reveals a role for Aurora B in correcting kinetochore-microtubule attachment and in maintaining the spindle assembly checkpoint. J Cell Bio 161: 281-294.

Hauser S, Wulfken LM, Holdenrieder S, Moritz R, Ohlmann CH, Jung V, Becker F, Herrmann E, Walgenbach-Brunagel G, von Ruecker A, Muller SC, Ellinger J (2012) Analysis of serum microRNAs (miR-26a-2* miR-191, miR-337-3p and miR-378) as potential biomarkers in renal cell carcinoma. Cancer Epidemiol 36: 391-394.

He L, Hannon GJ (2004) MicroRNAs: small RNAs with a big role in gene regulation. Nat Rev Genet 5: 522-531.

Honda R, Korner R, Nigg EA (2003) Exploring the functional interactions between Aurora B, INCENP, and survivin in mitosis. Mol Biol Cell 14 3325-3341.

Honma K, Nakanishi R, Nakanoko T, Ando K, Saeki H, Oki E, Iimori M, Kitao H, Kakeji Y, Maehara Y (2013) Contribution of Aurora-A and -B expression to DNA aneuploidy in gastric cancers. Surg Today 44(3): $454-461$.

Hontz AE, Li SA, Lingle WL, Negron V, Bruzek A, Salisbury JL, Li JJ (2007) Aurora a and $\mathrm{B}$ overexpression and centrosome amplification in early estrogen-induced tumor foci in the Syrian hamster kidney: implications for chromosomal instability, aneuploidy, and neoplasia. Cancer Res 67: 2957-2963.

Hua Z, Lv Q, Ye W, Wong CK, Cai G, Gu D, Ji Y, Zhao C, Wang J, Yang BB, Zhang Y (2006) MiRNA-directed regulation of VEGF and other angiogenic factors under hypoxia. PLoS One 1: e116.

Jurek A, Heldin CH, Lennartsson J (2011) Platelet-derived growth factorinduced signaling pathways interconnect to regulate the temporal pattern of Erk1/2 phosphorylation. Cell Signal 23: 280-287.

Kallio MJ, McCleland ML, Stukenberg PT, Gorbsky GJ (2002) Inhibition of aurora B kinase blocks chromosome segregation, overrides the spindle checkpoint, and perturbs microtubule dynamics in mitosis. Curr Biol 12: 900-905.

Kamei Y, Ohizumi H, Fujitani Y, Nemoto T, Tanaka T, Takahashi N, Kawada T, Miyoshi M, Ezaki O, Kakizuka A (2003) PPARgamma coactivator 1 beta/ERR ligand 1 is an ERR protein ligand, whose expression induces a high-energy expenditure and antagonizes obesity. Proc Natl Acad Sci USA 100: $12378-12383$.

Kressler D, Schreiber SN, Knutti D, Kralli A (2002) The PGC-1-related protein PERC is a selective coactivator of estrogen receptor alpha. J Biol Chem 277: 13918-13925.

Lee DY, Deng Z, Wang CH, Yang BB (2007) MicroRNA-378 promotes cell survival, tumor growth, and angiogenesis by targeting SuFu and Fus-1 expression. Proc Natl Acad Sci USA 104: 20350-20355.

Lengauer C, Kinzler KW, Vogelstein B (1997) Genetic instability in colorectal cancers. Nature 386: 623-627.

Li M, Fang X, Wei Z, York JP, Zhang P (2009) Loss of spindle assembly checkpoint-mediated inhibition of $\mathrm{Cdc} 20$ promotes tumorigenesis in mice. J Cell Biol 185: 983-994.

Liu H, Zhu L, Liu B, Yang L, Meng X, Zhang W, Ma Y, Xiao H (2012) Genome-wide microRNA profiles identify miR-378 as a serum biomarker for early detection of gastric cancer. Cancer Lett 316: 196-203.

Lovat F, Valeri N, Croce CM (2011) MicroRNAs in the pathogenesis of cancer. Semin Oncol 38: 724-733.

Musacchio A (2011) Spindle assembly checkpoint: the third decade. Philos Trans R Soc Lond B Biol Sci 366: 3595-3604.

Naume B, Borgen E, Kvalheim G, Karesen R, Qvist H, Sauer T, Kumar T, Nesland JM (2001) Detection of isolated tumor cells in bone marrow in early-stage breast carcinoma patients: comparison with preoperative clinical parameters and primary tumor characteristics. Clin Cancer Res 7: 4122-4129.
Naume B, Zhao X, Synnestvedt M, Borgen E, Russnes HG, Lingjaerde OC, Stromberg M, Wiedswang G, Kvalheim G, Karesen R, Nesland JM, Borresen-Dale AL, Sorlie T (2007) Presence of bone marrow micrometastasis is associated with different recurrence risk within molecular subtypes of breast cancer. Mol Oncol 1: 160-171.

Ota T, Suto S, Katayama H, Han ZB, Suzuki F, Maeda M, Tanino M, Terada Y, Tatsuka M (2002) Increased mitotic phosphorylation of histone H3 attributable to AIM-1/Aurora-B overexpression contributes to chromosome number instability. Cancer Res 62: 5168-5177.

Parker JS, Mullins M, Cheang MC, Leung S, Voduc D, Vickery T, Davies S, Fauron C, He X, Hu Z, Quackenbush JF, Stijleman IJ, Palazzo J, Marron JS, Nobel AB, Mardis E, Nielsen TO, Ellis MJ, Perou CM, Bernard PS (2009) Supervised risk predictor of breast cancer based on intrinsic subtypes. J Clin Oncol 27: 1160-1167.

Perou CM, Sorlie T, Eisen MB, van de Rijn M, Jeffrey SS, Rees CA, Pollack JR, Ross DT, Johnsen H, Akslen LA, Fluge O, Pergamenschikov A, Williams C, Zhu SX, Lonning PE, Borresen-Dale AL, Brown PO, Botstein D (2000) Molecular portraits of human breast tumours. Nature 406: $747-752$.

Pillai RS, Bhattacharyya SN, Filipowicz W (2007) Repression of protein synthesis by miRNAs: how many mechanisms? Trends Cell Biol 17: $118-126$.

Pinkas-Kramarski R, Shelly M, Guarino BC, Wang LM, Lyass L, Alroy I, Alimandi M, Kuo A, Moyer JD, Lavi S, Eisenstein M, Ratzkin BJ, Seger R, Bacus SS, Pierce JH, Andrews GC, Yarden Y (1998) ErbB tyrosine kinases and the two neuregulin families constitute a ligand-receptor network. Mol Cell Biol 18: 6090-6101.

Redova M, Poprach A, Nekvindova J, Iliev R, Radova L, Lakomy R, Svoboda M, Vyzula R, Slaby O (2012) Circulating miR-378 and miR-451 in serum are potential biomarkers for renal cell carcinoma. J Transl Med 10: $55-5876-10-55$

Rodriguez A, Griffiths-Jones S, Ashurst JL, Bradley A (2004) Identification of mammalian microRNA host genes and transcription units. Genome Res 14: 1902-1910.

Sorlie T, Perou CM, Tibshirani R, Aas T, Geisler S, Johnsen H, Hastie T, Eisen MB, van de Rijn M, Jeffrey SS, Thorsen T, Quist H, Matese JC, Brown PO, Botstein D, Lonning PE, Borresen-Dale AL (2001) Gene expression patterns of breast carcinomas distinguish tumor subclasses with clinical implications. Proc Natl Acad Sci USA 98: 10869-10874.

Sotillo R, Hernando E, Diaz-Rodriguez E, Teruya-Feldstein J, Cordon-Cardo C, Lowe SW, Benezra R (2007) Mad2 overexpression promotes aneuploidy and tumorigenesis in mice. Cancer Cell 11: 9-23.

Sotillo R, Schvartzman JM, Socci ND, Benezra R (2010) Mad2-induced chromosome instability leads to lung tumour relapse after oncogene withdrawal. Nature 464: 436-440.

Valentin MD, da Silva SD, Privat M, Alaoui-Jamali M, Bignon YJ (2012) Molecular insights on basal-like breast cancer. Breast Cancer Res Treat 134: $21-30$.

van der Waal MS, Hengeveld RC, van der Horst A, Lens SM (2012) Cell division control by the Chromosomal Passenger Complex. Exp Cell Res 318: 1407-1420.

Wang IC, Chen YJ, Hughes D, Petrovic V, Major ML, Park HJ, Tan Y, Ackerson T, Costa RH (2005) Forkhead box M1 regulates the transcriptional network of genes essential for mitotic progression and genes encoding the SCF (Skp2-Cks1) ubiquitin ligase. Mol Cell Biol 25: 10875-10894.

Weaver BA, Silk AD, Montagna C, Verdier-Pinard P, Cleveland DW (2007) Aneuploidy acts both oncogenically and as a tumor suppressor. Cancer Cell 11: 25-36.

Zeitlin SG, Shelby RD, Sullivan KF (2001) CENP-A is phosphorylated by Aurora B kinase and plays an unexpected role in completion of cytokinesis. J Cell Biol 155: 1147-1157.

This work is published under the standard license to publish agreement. After 12 months the work will become freely available and the license terms will switch to a Creative Commons AttributionNonCommercial-Share Alike 3.0 Unported License.

Supplementary Information accompanies this paper on British Journal of Cancer website (http://www.nature.com/bjc) 